\title{
Parámetros de Calidad y Metodologías para Determinar las Propiedades Físicas de Alimentos Extruidos para Peces
}

\author{
José L. Hoyos ${ }^{(1)}$, Héctor S. Villada(1), Alejandro Fernández ${ }^{(2)}$ y Rodrigo Ortega-Toro(1) \\ (1) Facultad de Ciencias Agrarias. Departamento de Agroindustria. Universidad del Cauca. Calle 5 No. 4 - \\ 70. Popayán. Colombia. (e-mail: jlhoyos@unicauca.edu.co) \\ (2) Facultad de Ingeniería. Escuela de Ingeniería de Alimentos. Universidad del Valle. Edificio 338 Segundo \\ Piso Oficina 2007. Santiago de Cali. Colombia
}

Recibido Feb. 13, 2017; Aceptado Mar. 27, 2017; Versión final May. 31, 2017, Publicado Oct. 2017

\begin{abstract}
Resumen
El presente trabajo relaciona los métodos tradicionales usados para analizar la calidad física de un alimento extruido para peces, como dureza, durabilidad, estabilidad en agua, velocidad de hundimiento, densidad aparente, capacidad de absorción-pérdida de aceite y porosidad como métodos para en el control de su producción a nivel industrial. Las propiedades físicas de los pellets son relevantes para la toma de decisiones relacionadas con las condiciones de procesamiento, transporte, almacenamiento, aprovechamiento biológico del animal y evaluación de nuevas materias primas y aditivos. Existen diversos métodos para determinar la calidad física de los pellets. Sin embargo, en su mayoría se relacionan con alimentación de animales terrestres, los cuales no son apropiados para la alimentación de peces. Estos requieren condiciones de resistencia al estrés mecánico y al mismo tiempo presentar una textura y tamaño que facilite la ingesta adecuada del alimento en el agua.
\end{abstract}

Palabras clave: dureza; durabilidad; velocidad de hundimiento; densidad aparente; porosidad

\section{Physical Quality of Extruded Aquafeeds. Effect of Formulation and Processing Conditions}

\begin{abstract}
The present work relates the traditional methods used to analyze the physical quality of fish extruded food, such as hardness, durability, water stability, sinking speed, bulk density, oil absorption and loss capacity and porosity as methods for the control of Its production at an industrial level. The physical properties of the pellets are relevant for decision making related to the conditions of processing, transport, storage, biological use of the animal and evaluation of new raw materials and additives. There are several methods for determining the physical quality of the pellets. However, they are mostly related to feeding of terrestrial animals, which are not suitable for feeding fish. These require conditions of resistance to mechanical stress and at the same time should have a texture and size that facilitates the adequate intake of food in the water.
\end{abstract}

Keywords: hardness; durability; sinking velocity; bulk density; porosity 


\section{INTRODUCCIÓN}

La producción mundial de acuicultura alcanzó 52.5 millones de toneladas, creciendo a una tasa anual de 8.4\% e incrementándose casi 4 veces desde 1995 (7.6 millones de toneladas) hasta el 2008 (29.3 millones de toneladas) (FAO, 2013). La harina y aceite de pescado son los alimentos de mayor demanda en este sector, sin embargo, actualmente se están investigando alimentos para peces a base de ingredientes alternativos como plantas, microorganismos y otras fuentes de proteína animal (Sørensen, 2012). Para estos desarrollos es muy importante la calidad fisicoquímica y estructural de los alimentos alternativos siendo algunas de las pruebas más comunes la fuerza de tensión a la fractura, dureza, durabilidad, estabilidad en agua, velocidad de hundimiento, densidad aparente, absorción y pérdida de grasa (Thomas y van der Poel, 1996; Sørensen, 2012). Algunos autores como Hilton et al. (1981) han estudiado diferentes procesos de obtención de pellets como extrusión y peletizado por vapor, observando que los pellets extruidos eran más durables, tenían mayor estabilidad en agua y absorbían mayor cantidad de agua. Otros aspectos importantes a tener en cuenta son las condiciones de proceso y los ingredientes usados en las formulaciones (Thomas et al., 1997).

En el presente trabajo se describen metodologías comúnmente usados para evaluar las propiedades físicas de alimentos extruidos. También se presenta un análisis sobre el efecto que tiene las diferentes formulaciones y condiciones de extrusión sobre las propiedades físicas de los productos. Pocas publicaciones presentan información de las propiedades físicas del alimento, requiriéndose la estandarización de métodos que permitan describir las interacciones entre los ingredientes y la elaboración en las propiedades físicas y las posibles repercusiones en los parámetros zootécnicos. Las propiedades de las dietas deben determinarse de forma rutinaria, en particular si se investigan nuevos ingredientes 0 condiciones de procesamiento, requiriendo métodos estandarizados para su evaluación (Sorensen, 2012). Además de micronutrientes, el alimento para peces contiene macromoléculas como almidón y proteína de origen animal y vegetal cuya interacción afecta directamente sus propiedades físicas (Chen et al., 2010), como la porosidad que permite una buena absorción de aceite y una estructura estable que permanezca durante el almacenamiento, transporte y la alimentación neumática del producto (Draganovic et al., 2011; Aarseth 2004; Aarseth et al., 2006a).

\section{PARÁMETROS DE CALIDAD}

A continuación se describe los parámetros de calidad física de alimentos extruidos para peces comúnmente reportados en literatura.

\section{Ensayo de fuerza de tensión y módulo elástico}

La fuerza de tensión a la fractura o dureza es definida como la máxima fuerza necesaria para romper un pellet (Thomas y Van der Poel, 1996). Por su forma cilíndrica, el método usado para determinar la dureza es la compresión diametral, para lo cual se suele usar un analizador de textura con platos paralelos lisos obteniendo la fuerza máxima reportadas en unidades de fuerza ( $N, \mathrm{~K}-\mathrm{f})$, como se muestra en la Figura 1.
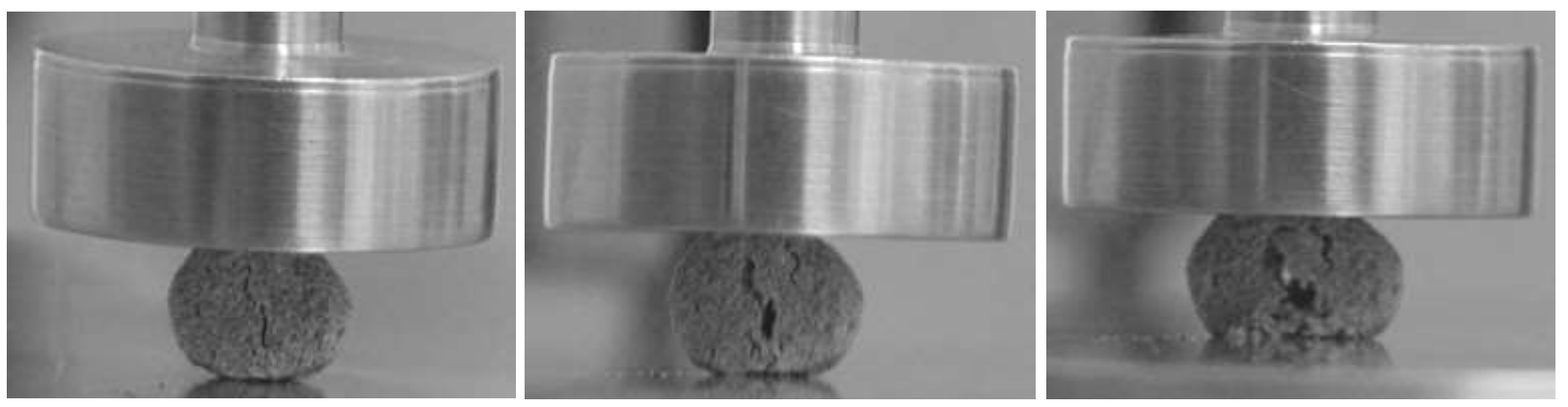

Fig. 1: Pellet bajo carga de compresión que crea una fuerza de tensión en el centro de la partícula

Aarseth et al. (2006b) estudiaron el efecto de la temperatura de extrusión en la fuerza de tensión de pellets considerando el análisis Weibull para la interpretación de los datos. Este análisis estadístico es una herramienta para elucidar la relación entre las condiciones de procesado, las materias primas y algunos parámetros de calidad física de los productos finales. Los parámetros de la distribución de probabilidad ajustada se relacionan directamente con las propiedades mecánicas de los pellets. Las temperaturas de extrusión usadas en su estudio fueron $100^{\circ} \mathrm{C}$ y $140^{\circ} \mathrm{C}$. Observaron que los pellets extruidos a temperaturas más altas mostraron menor fuerza aunque fueron más homogéneos. 
En la Tabla 1 se resumen algunas características de alimento para peces como la fuente de proteína, las formulaciones y condiciones de proceso, los valores de dureza de los pellets y el instrumento utilizado para determinar la dureza

Tabla 1: Valores de dureza de alimentos extruidos para peces a partir de diferentes formulaciones y condiciones de proceso

\begin{tabular}{|c|c|c|c|c|c|}
\hline $\begin{array}{l}\text { Fuente de } \\
\text { proteína }\end{array}$ & \multicolumn{2}{|c|}{$\begin{array}{l}\text { Formulaciones y condiciones de } \\
\text { proceso }\end{array}$} & Dureza & Instrumento & Referencia \\
\hline $\begin{array}{l}\text { Dieta adicionada } \\
\text { con levadura roja }\end{array}$ & $\begin{array}{l}\text { Temperatura } \\
\text { de extrusión } \\
100^{\circ} \mathrm{C} \\
100^{\circ} \mathrm{C} \\
140^{\circ} \mathrm{C} \\
140^{\circ} \mathrm{C}\end{array}$ & $\begin{array}{l}\text { Grado de digestión } \\
\text { enzimática de la } \\
\text { pared celular de } \\
\text { levaduras } \\
45 \% \\
97 \% \\
45 \% \\
97 \%\end{array}$ & $\begin{array}{l}\text { Valores } \\
\text { expresados como } \\
\text { resistencia a la } \\
\text { tracción } \\
356 \pm 13 \mathrm{KPa} \\
394 \pm 14 \mathrm{KPa} \\
330 \pm 11 \mathrm{KPa} \\
358 \pm 14 \mathrm{KPa}\end{array}$ & $\begin{array}{l}\text { Instrumento } \\
\text { Lloyd }\end{array}$ & $\begin{array}{l}\text { Aarseth et al. } \\
(2006 b)\end{array}$ \\
\hline $\begin{array}{l}\text { Harina de } \\
\text { pescado }\end{array}$ & \multicolumn{2}{|c|}{$\begin{array}{l}\text { Contenido de humedad } 26 \mathrm{~g} / 100 \mathrm{~g} \\
\text { (base húmeda) } \\
\text { Harina de pescado: gluten de trigo } \\
(1: 1) \\
\text { Harina de pescado: concentrado de } \\
\text { proteína de soya ( } 1: 1) \\
\text { Contenido de humedad } 32 \mathrm{~g} / 100 \mathrm{~g} \\
\text { (base húmeda) } \\
\text { Harina de pescado: gluten de trigo } \\
(1: 1) \\
\text { Harina de pescado: concentrado de } \\
\text { proteína de soya ( } 1: 1)\end{array}$} & $\begin{array}{l}8139 \pm 196 N \\
7159 \pm 294 N\end{array}$ & $\begin{array}{l}\text { Analizador } \\
\text { de textura }\end{array}$ & $\begin{array}{l}\text { Draganovic et } \\
\text { al. (2011) }\end{array}$ \\
\hline Dieta & \multicolumn{2}{|c|}{$\begin{array}{l}\text { Porcentaje de materia seca } \\
96 \% \\
94 \% \\
91 \%\end{array}$} & $\begin{array}{l}38 \pm 5 N \\
33 \pm 4 N \\
50 \pm 3 N\end{array}$ & $\begin{array}{l}\text { Analizador } \\
\text { de textura }\end{array}$ & $\begin{array}{l}\text { Oehme et al. } \\
(2014)\end{array}$ \\
\hline $\begin{array}{l}\text { Harina de } \\
\text { pescado }\end{array}$ & \multicolumn{2}{|c|}{$\begin{array}{l}\text { Variación en propiedades } \\
\text { fisicoquímicas de la harina de } \\
\text { pescado }\end{array}$} & $4.9-133.4 \mathrm{~N}$ & $\begin{array}{l}\text { Medidor de } \\
\text { dureza }\end{array}$ & $\begin{array}{l}\text { Samuelsen et } \\
\text { al. (2013) }\end{array}$ \\
\hline $\begin{array}{l}\text { Harina de } \\
\text { pescado }\end{array}$ & \multicolumn{2}{|c|}{$\begin{array}{l}\text { Inclusión de harina de soja } \\
\text { desengrasada ( } 40 \% \text { de sustitución } \\
\text { de proteína) } \\
\text { Harina de pescado (control) } \\
\text { Harina de soja tostada al } 40 \% \\
\text { Harina de soja sin tostar al } 40 \%\end{array}$} & $\begin{array}{l}20 \pm 2 \mathrm{~N} \\
36 \pm 0.8 \mathrm{~N} \\
42 \pm 3 \mathrm{~N}\end{array}$ & $\begin{array}{l}\text { Instrumento } \\
\text { Lloyd }\end{array}$ & $\begin{array}{l}\text { Sørensen et } \\
\text { al. (2009) }\end{array}$ \\
\hline $\begin{array}{l}\text { Harina de } \\
\text { pescado }\end{array}$ & \multicolumn{2}{|c|}{$\begin{array}{l}\text { Almidón pre-gelatinizado de papa } \\
\text { Configuración de tornillo LRLR } \\
\text { Sin inyección de vapor al barril }\end{array}$} & $\begin{array}{l}33 \mathrm{~N} \\
30 \mathrm{~N} \\
28 \mathrm{~N}\end{array}$ & $\begin{array}{l}\text { Analizador } \\
\text { de textura }\end{array}$ & $\begin{array}{l}\text { Sørensen et } \\
\text { al. }(2010)\end{array}$ \\
\hline
\end{tabular}

Draganovic et al. (2011) estudiaron los efectos de la harina de pescado, gluten de trigo, concentrado de proteína de soya y humedad en los parámetros del sistema de extrusión y calidad técnica de alimento para peces. Se observó que los productos con mayor fuerza de fractura se obtuvieron con los contenidos más altos de gluten de trigo y concentrado de proteína de soya con mediano contenido de humedad. Además, encontraron que la fuente de proteína afecta directamente las propiedades finales del alimento extruido. Oehme et al. (2014) estudiaron el efecto del contenido de humedad de dietas extruidas en las propiedades físicas y nutricionales del alimento para peces, evaluando diferentes tiempos de secado. Reportaron que alimentos de alta dureza pueden hacer que el consumo disminuya y en consecuencia la velocidad de crecimiento. Samuelsen et al. (2013) estudiaron el impacto de la variabilidad de las propiedades fisicoquímicas de la harina de pescado en el proceso de extrusión, gelatinización del almidón, durabilidad y dureza del pellet. Las mejoras en la dureza se asociaron al descenso en la capacidad de ligar agua, descenso de $\mathrm{pH}$, descenso en el nivel de proteína no soluble, incremento en el nivel de sal e incremento en el nivel de fracciones de proteína soluble en agua. 
Por otro lado, Sørensen et al. (2009) estudiaron el efecto de la harina de soja sobre las propiedades físicas de harina de pescado extruida. Observaron que la sustitución de proteína de la harina de pescado por harina de soja promovía el incremento de la dureza. Posteriormente, Sørensen et al. (2010) estudiaron la fuente de almidón, configuración del tornillo y el efecto de la inyección de vapor en el barril sobre las propiedades físicas del alimento extruido para peces. Compararon diferentes fuentes de almidón observando que el almidón pregelatinizado de papa era el más adecuado para el proceso.

\section{Ensayo de Compresión}

La normativa que regula este ensayo es la Norma ASAE S368.3 (1995). Teniendo en cuenta que el alimento para peces extruido tiene forma cilíndrica el ensayo de compresión se debe llevar a cabo usando una máquina de ensayos equipada con platos paralelos. La Figura 2 muestra esquemáticamente el ensayo de fuerza deformación y la fórmula para el cálculo del módulo elástico aparente para materiales cilíndricos.

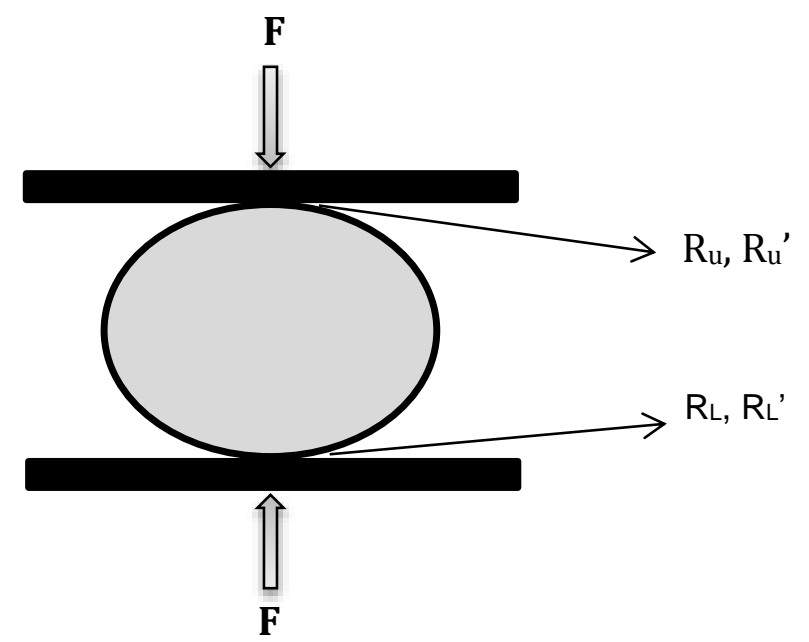

Fig. 2: Ensayo de fuerza deformación y cálculo del módulo elástico aparente para materiales cilíndricos (Adaptado de Norma ASAE S368.3, 1995).

$$
E=\frac{0.338 F\left(t-P^{2}\right)}{D^{\frac{3}{2}}}\left|K_{u}\left(\frac{1}{R_{u}}+\frac{1}{{R_{u}^{\prime}}_{u}}\right)^{\frac{1}{3}}+K_{L}\left(\frac{1}{R_{L}}+\frac{1}{{R^{\prime}}_{L}}\right)^{\frac{1}{3}}\right|^{\frac{3}{2}}
$$

En la ecuación 1, E es el módulo de elasticidad aparente (Pa), $D$ es la deformación $(m)$, P es el coeficiente de Poisson, $F$ es la fuerza $(N), R_{u}$ y $R_{u}$ ' son los radios de curvatura en el punto de contacto para la parte superior de la superficie convexa $(m), R_{L}$ y $R_{L}$ ' son los radios de curvatura en el punto de contacto para la parte inferior de la superficie convexa $(m)$, $D$ es el diámetro de la curvatura de la esfera $(m)$, las constantes $\mathrm{K}_{\mathrm{u}}$ y $\mathrm{K} \mathrm{L}$ son calculadas a partir del $\cos \theta$ de acuerdo a la norma ASAE S368.3 de 1995. Algunos autores usan el análisis estadístico Weibull para obtener un modelo matemático que explica porque pellets aparentemente idénticos muestran alta distribución de fuerza, debido a que su estructura está conformada por partículas ordenadas aleatoriamente en diferentes direcciones, aportando una medida de homogeneidad y de dispersión de las fracturas o tamaños de poros en el material, contribuyendo a mejorar el entendimiento de la calidad técnica del pellet y de qué forma influye el proceso en el producto final (Weibull, 1939; Acosta et al., 2006; Aarseth et al., 2006b).

Otros autores como Haubjerg et al. (2013) han estudiado las propiedades reológicas de extruídos para alimentación de peces, como indicador de los procesos fisicoquímicos que afectan su calidad. Ellos llevan a cabo ensayos de compresión mediante análisis de perfil de textura. En esta técnica se comprimen las muestras al menos dos veces simulando el movimiento de las mandíbulas. Se comprimen las muestras hasta cierto porcentaje de deformación y, luego de un tiempo de espera se retira el esfuerzo aplicado y se repiten los ciclos. Muy útil para obtener valores de cohesividad, dureza, resiliencia, pegajosidad y fracturabilidad. Otro ensayo que se suele hacer es mantener cierto grado de compresión durante un tiempo determinado. La fuerza que se registra describirá la habilidad que tienen los pellets de soportar deformaciones plásticas o viscoelásticas. Haubjerg et al. (2013) encontraron que incrementos en la elasticidad de los pellets puede llevar a disminución de la durabilidad mecánica y también que incrementos en la cohesividad, rigidez y dureza de los pellets conlleva a aumento en su durabilidad. 


\section{Durabilidad}

La durabilidad es la cantidad de finos producidos de una muestra de pellets después de empezar a someterse a agitación mecánica o neumática (Thomas \& Van der Poel 1996; Kaliyan \& Morey). En la literatura se han reportado diferentes métodos para determinar la durabilidad de alimento para peces. La caja de golpeo y Holmen Tester pueden causar pérdida de aceite en alimentos de alta energía por eso se recomienda usarla en alimentos que no tengan recubrimiento de aceite. Para alimentos recubiertos con aceite se recomienda el uso del Doris Tester.

El método de la caja de golpeo. Es un método ampliamente aceptado siendo una norma en la industria de Norte América (ASAE S269.4, 1997). Es usado para simular la formación de finos durante la manipulación mecánica, calculando el índice de durabilidad de los pellets (PDI) como el porcentaje de los pellets retenidos después de 10 minutos de prueba dividido por el total de la masa de los pellets inicial (500 g generalmente). Mina-Boac et al. (1996) determinaron la durabilidad de pellets a base de harina de maíz sometidos a manipulación continua en un elevador mecánico, los pellets se trasfirieron alternativamente entre dos cajas de almacenamiento para un total de 8 transferencias, la formulación de los pellets fue constante. Se obtuvo un PDI promedio de $92.9 \% \pm 0.6 \%$, sin reportar diferencias significativas entre los tratamientos. Sørensen et al. (2010) llevaron a cabo un estudio del efecto del proceso de extrusión de harina de pescado sobre la durabilidad pellets no recubiertos con aceite, mediante el método Holmen y de la caja de golpeo. Mediante el método Holmen determinaron un rango amplio de durabilidad entre $37.1 \%$ y el $79.1 \%$, en contraste con el método de caja de golpeo, el cual dio por resultado un rango estrecho entre $98.4 \%$ y el $98.8 \%$. Esto indica que el método Holmen es más efectivo para calcular la durabilidad de pellets no recubiertos.

La prueba de durabilidad Holmen. Fue desarrollada para evaluar el efecto de las fuerzas de impacto y cizalla durante el transporte neumático, es comúnmente usado en Europa ya que simula el transporte neumático en los molinos europeos (Mina-Boac et al., 1996). Se remueven los finos a medida que se forman y los pellets son retirados al final del ciclo. Los pellets restantes son usados para calcular el PDI. Aarseth et al. (2006b) usaron este método para evaluar el efecto de la inclusión de levadura roja y temperatura de extrusión sobre pellets, encontrando durabilidades entre el $96.4 \%$ y $97.2 \%$. Otros investigadores (Kraugerud et al., 2011) encontraron valores de durabilidad entre el 66 y $95 \%$ dependiendo de la fuente de proteína (gluten de maíz, girasol, lupino y colza) y de la fuente de almidón (guisante, frijol entero, frijol descascarado y trigo) usados en alimentos extruido para peces. La proteína que confirió mayor durabilidad fue el gluten de maíz $(92 \% \pm 0.6 \%)$ y la mejor fuente de almidón fue el frijol entero $(95 \% \pm 3 \%)$, observándose una correlación entre durabilidad y dureza de los pellets, tal como reportan otros autores (Wood, 1987; Øvrum y Storebakken, 2007). Samuelsen et al. (2013) emplearon el Holmen tester para determinar la durabilidad de pellets recubiertos, observando que la adición de proteínas solubles en agua a la harina de pescado o realizar una pre-mezcla de las formulaciones antes de la extrusión incrementa la durabilidad de los pellets, los resultados de este estudio fueron similares a los reportados en estudios anteriores por Samuelsen y Oterhals (2000).

Doris Tester. Esta técnica simula las tensiones a las que son expuestos los pellets en los dispositivos de alimentación neumática. Este aparato está diseñado con un tornillo Arquímedes que alimenta los pellets a un aspa simulando el proceso de degradación de los pellets por impacto y cizalla (Aas et al., 2011b). Morken et al. (2011) usaron el Doris Tester para determinar la durabilidad de harina de pescado con diferentes formulaciones y condiciones de procesado. Los resultados mostraron que al aumentar la temperatura del proceso, de $110^{\circ} \mathrm{C}$ a $141^{\circ} \mathrm{C}$, incrementaba la durabilidad del material, aunque estos resultados contrastan con los datos obtenidos por Aarseth et al. (2006b), quienes observaron que la temperatura de extrusión era inversa a la durabilidad. Por otro lado, las condiciones de secado es un factor determinante en las propiedades finales de los pellets, algunos investigadores han determinado aumentos hasta de un 62 unidades porcentuales en los valores de durabilidad al reducir la humedad, en la etapa de secado, desde el $96 \%$ hasta el $91 \%$ en base seca (Oehme et al., 2014). La Tabla 2 muestra algunos valores de durabilidad reportados en bibliografía.

\section{Estabilidad en agua}

Es un parámetro importante para el trabajo con peces de alimentación lenta ya que el alimento debe sumergirse durante horas con la mínima pérdida de nutrientes. Así mismo es importante porque imita el patrón de desintegración del alimento en el tracto gastrointestinal (Aas et al., 2011a; Sørensen, 2012; Oehme et al., 2014). La estabilidad en agua se calcula como la diferencia porcentual de peso antes y después de la prueba, expresada como porcentaje de pérdida de materia seca (Fagbenro y Jauncey, 1995). Algunos autores (Oehme et al., 2014) diferencian entre la prueba de estabilidad en agua a tiempo corto (60$120 \mathrm{~min}$ ) y largo (240 min). La estabilidad de los pellets en el agua afecta el consumo del alimento y por tanto la tasa de crecimiento específico de los peces. 
Tabla 2: Valores de durabilidad y desviación estándar de alimentos extruidos para peces a partir de diferentes formulaciones y condiciones de proceso

\begin{tabular}{|c|c|c|c|}
\hline $\begin{array}{l}\text { Fuente de } \\
\text { proteína/método usado }\end{array}$ & Formulaciones y condiciones de proceso & Durabilidad (\%) & Referencia \\
\hline $\begin{array}{l}\text { Dieta adicionada con } \\
\text { levadura roja/ Holmen }\end{array}$ & $\begin{array}{l}\text { Temperatura de extrusión } \\
100^{\circ} \mathrm{C} \\
140^{\circ} \mathrm{C}\end{array}$ & $\begin{array}{l}97.2 \\
96.4\end{array}$ & $\begin{array}{l}\text { Aarseth et al. } \\
(2006 b)\end{array}$ \\
\hline $\begin{array}{l}\text { Pellets a base de } \\
\text { harina de maíz/método } \\
\text { de caja de golpeo }\end{array}$ & $\begin{array}{l}\text { Diferentes zonas de transferencia en un } \\
\text { elevador mecánico. }\end{array}$ & $92.9 \pm 0.6$ & $\begin{array}{l}\text { Mina-Boac et al. } \\
\text { (1996) }\end{array}$ \\
\hline $\begin{array}{l}\text { Harina de pescado } \\
\text { /Holmen }\end{array}$ & $\begin{array}{l}\text { Fuente de proteína: } \\
\text { Gluten de maíz } \\
\text { Lupino } \\
\text { Fuente de almidón: } \\
\text { Frijol entero } \\
\text { Guisantes }\end{array}$ & $\begin{array}{l}92 \pm 0.6 \\
66 \pm 2.2 \\
95 \pm 0.3 \\
67 \pm 1.3\end{array}$ & $\begin{array}{l}\text { Kraugerud et al. } \\
\text { (2011) }\end{array}$ \\
\hline $\begin{array}{l}\text { Harina de pescado/ } \\
\text { Doris Tester }\end{array}$ & $\begin{array}{l}\text { Harina de pescado a } 110^{\circ} \mathrm{C} \\
\text { Harina de pescado a } 141^{\circ} \mathrm{C}\end{array}$ & $\begin{array}{l}92 \\
94.2\end{array}$ & $\begin{array}{l}\text { Morken et al. } \\
\text { (2011) }\end{array}$ \\
\hline $\begin{array}{l}\text { Harina de pescado } \\
\text { Doris Tester }\end{array}$ & $\begin{array}{l}\text { Humedad en base seca } \\
96 \% \\
94 \% \\
91 \%\end{array}$ & $\begin{array}{l}37.9 \pm 0.9 \\
73.6 \pm 0.3 \\
98.8 \pm 0.1\end{array}$ & $\begin{array}{l}\text { Oehme et al. } \\
(2014)\end{array}$ \\
\hline $\begin{array}{l}\text { Harina de } \\
\text { pescado/Ligno Tester }\end{array}$ & $\begin{array}{l}\text { Harina de pescado } \\
\text { Substitución de } 350 \mathrm{~g} / \mathrm{Kg} \text { de proteína de } \\
\text { guisante } \\
\text { Substitución de } 500 \mathrm{~g} / \mathrm{Kg} \text { de proteína de } \\
\text { guisante }\end{array}$ & $\begin{array}{l}87.5 \\
97.2 \\
96.9\end{array}$ & $\begin{array}{l}\text { Øverland et al. } \\
(2009)\end{array}$ \\
\hline $\begin{array}{l}\text { Harina de pescado/ } \\
\text { Holmen }\end{array}$ & $\begin{array}{l}\text { Variación en propiedades fisicoquímicas de } \\
\text { la harina de pescado }\end{array}$ & $65 \pm 41$ & $\begin{array}{l}\text { Samuelsen et al. } \\
(2013)\end{array}$ \\
\hline $\begin{array}{l}\text { Harina de } \\
\text { pescado/Holmen }\end{array}$ & $\begin{array}{l}\text { Inclusión de harina de soja desengrasada } \\
\text { (40\% de aminoácido sustituidos) } \\
\text { Harina de pescado (control) } \\
\text { Harina de soja tostada al } 40 \% \\
\text { Harina de soja sin tostar al } 40 \%\end{array}$ & $\begin{array}{l}\text { Ensayo } 90 \mathrm{~s} \\
\sim 63 \\
\sim 80 \\
\sim 82\end{array}$ & $\begin{array}{l}\text { Sørensen et al. } \\
\text { (2009) }\end{array}$ \\
\hline $\begin{array}{l}\text { Harina de pescado/ } \\
\text { Holmen y caja de } \\
\text { golpeo }\end{array}$ & $\begin{array}{l}\text { Holmen: } \\
\text { Almidón pre-gelatinizado de papa } \\
\text { Configuración de tornillo LRLR* } \\
\text { Caja de golpeo: } \\
\text { Almidón pre-gelatinizado de papa }\end{array}$ & $\begin{array}{l}79.1 \\
76.1 \\
98.8 \\
98.7\end{array}$ & $\begin{array}{l}\text { Sørensen et al. } \\
(2010)\end{array}$ \\
\hline
\end{tabular}

Baeverfjord et al. (2006) estudiaron la estabilidad en agua de alimentos extruidos y su efecto nutricional en trucha arco iris. El alimento fue extruido bajo diferentes condiciones de proceso para obtener distinta estabilidad en agua (alta y baja), aunque no diferían notablemente en su composición química. Los pellets se sometieron a esta prueba con agitación durante $240 \mathrm{~min}$. En la Figura 3 se puede observar como los pellets con alta estabilidad (izquierda) conservan su estructura después de la prueba, al contrario a los pellets de baja estabilidad (derecha). Después de la prueba, se pudo recuperar un $81.1 \pm 0.3 \%$ de materia seca y $84.9 \pm 0.7 \%$ de lípidos en los pellets de alta estabilidad. Por otro lado, los pellets con baja estabilidad en agua conservaron un $42.3 \pm 3.9 \%$ de la materia seca y un $46.0 \pm 4.7 \%$ de lípidos. 

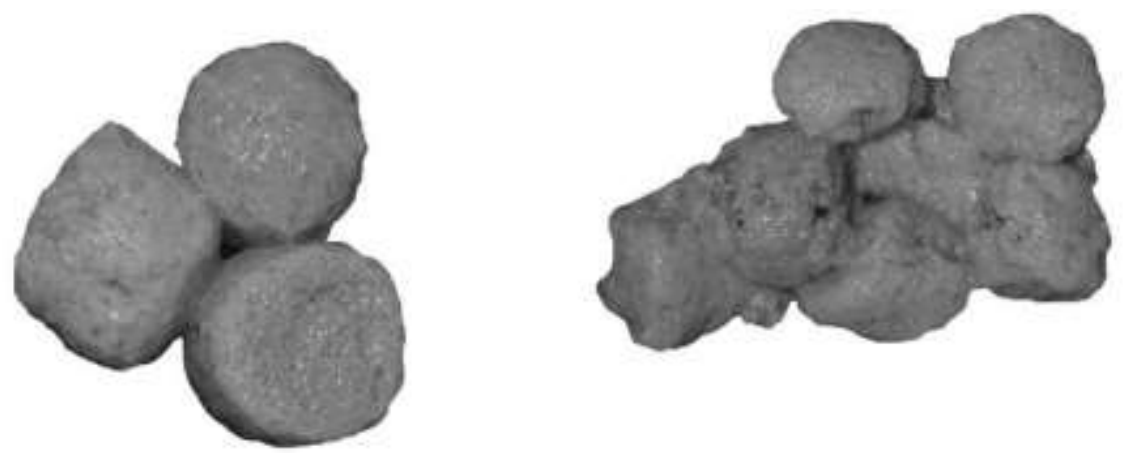

Fig. 3: Desintegración de pellets en la prueba de estabilidad en agua (240 min). Izquierda: pellets de alta estabilidad en agua; derecha: pellets de baja estabilidad en agua (Adaptado de Baeverfjord et al., 2006)

Por otro lado, Morken et al. (2011) observaron que la adición de proteína de cebada disminuye significativamente la estabilidad en agua $(77 \%$ - $91 \%$ de la materia seca recuperada) comparada con dietas de harina de pescado $(90.5 \%-92.2 \%$ de materia seca recuperada). Esto probablemente debido a que la mayor expansión sufrida por las dietas que contenían proteína de cebada promovió la porosidad del material y durante la prueba el agua tenía más espacios libres para circular y se pudo difundir más fácilmente en la matriz provocando menor estabilidad en el agua. Zhang et al. (2012a) optimizaron las mezclas de concentrados de proteína vegetal en extruidos libres de harina de pescado. Usaron concentrados de proteína de guisante, canola, papa y soya fortificando las dietas obtenidas con amino ácidos esenciales y taurina. La harina de pescado (control) fue la formulación más estable en agua (86.5\%). Las dietas a base de proteína de guisante $(85.6 \%)$ y proteína de canola $(84.2 \%)$ mostraron resultados similares y finalmente la dieta a base de proteína de soya fue la menos estable en agua (62.6\%). Otros investigadores (Fagbenro y Jauncey, 1995) estudiaron la estabilidad en agua, la lixiviación de nutrientes y propiedades nutricionales de ensilaje fermentado extruido. Para ello evaluaron inclusiones de carboximetil celulosa, almidón de maíz, goma guar y gluten de trigo como aglutinantes en ensilaje de pescado extruido.

\section{Aglutinantes comúnmente usados en formulación de alimentos extruidos}

Los aglutinantes presentes en la matriz deben promover el incremento de la afinidad entre los diferentes componentes de las formulaciones. Esto puede ser llevado a cabo mediante factores físicos o químicos. Entre los factores físicos se destaca el cambio de las propiedades reológicas del medio, como el caso del incremento de la viscosidad cuando se incorporan moléculas como el almidón, proteínas, derivados de celulosa, gomas y sólidos solubles (Serna-Cock et al., 2010; Sørensen et al., 2010; Kraugerud et al. 2011; Osorio et al., 2015; Giraldo et al., 2017). En cuanto a los factores químicos, algunas moléculas o sustancias como las proteínas, melaza (alto contenido de glucosa y fructosa) y carbonato de calcio (Pantoja et al., 2011; Oterhals y Samuelsen, 2015; Vanegas y Ramírez, 2015) pueden incrementar interacciones moleculares como puentes de hidrogeno, fuerzas de van der Waals, interacciones hidrofóbicas o modificar las cargas eléctricas del medio, mejorando la afinidad entre los componentes de la formulación. Derby et al. (2016), reportaron que el gluten, almidón y harina de trigo, en condiciones de hidratación y cocción (como en el caso de la extrusión), forman un efectivo aglutinante del pellet que limita la lixiviación de sus componentes. En la Tabla 3 se muestran un listado de aglutinantes reportados en bibliografía que suelen usarse en las formulaciones de alimentos extruido para peces.

\section{Velocidad de hundimiento}

La velocidad de hundimiento mide el tiempo que pellets individuales tardan en recorrer una distancia determinada en una columna de agua bajo condiciones de salinidad y temperatura controladas. Para esta prueba los pellets son seleccionados de forma aleatoria y los datos son reportados como $\mathrm{cm} / \mathrm{s}$ (Lekang et al. 1991; Sørensen, 2012). Los factores que suelen afectar este parámetro suelen ser estructurales como la expansión y la porosidad del pellet afectando también su densidad aparente (Øverland et al., 2007; Kraugerud et al., 2011; Draganovic et al., 2011; Tyapkova et al., 2016). En este sentido, el tratamiento térmico del proceso juega un papel fundamental. La proteína y el almidón contenido en las dietas sufren diferentes grados de coagulación y gelatinización respectivamente, dependiendo de la intensidad del tratamiento térmico. Entre menor sea la temperatura-presión-tiempo empleados menores serán las transformaciones de las macromoléculas y menor será la expansión de los pellets dando lugar a mayores velocidades de hundimiento (Øverland et al., 2007). En general, para conseguir velocidades de hundimiento lentas es necesario densidades aparentes próximas a $520 \mathrm{~g} / \mathrm{L}$ y recubrimiento con lípidos (Zhang et al., 2012a, b). 


\section{Densidad aparente (Da)}

Generalmente la densidad aparente se determina según la norma ISO 5311-1992. Se determina mediante el llenado de un cilindro volumétrico con una cantidad de pellet conocida. Se debe llenar completamente el cilindro hasta el borde superior, para enrasar el borde se usa una espátula suavemente. Entonces se toma el peso del cilindro lleno en una balanza. La densidad es calculada como la masa de la muestra por la unidad de volumen de la muestra (g/L) (Aarseth et al., 2006b). La densidad aparente es importante porque mediante esta se puede controlar la velocidad de hundimiento y la flotabilidad (Chevanan et al., 2007, 2009; Sørensen, 2012) y está relacionada con la capacidad de expansión durante la extrusión (Aarseth et al., 2006b; Glencross et al. 2011). La macromolécula más estrechamente ligada a este fenómeno es el almidón (Chinnaswamy, 1993). Los procesos de expansión dependen de dos fenómenos. En primer lugar, el proceso de extrusión y la recuperación elástica cuando pasa desde alta presión en el dado a presión ambiental. Y en segundo lugar, la expansión promovida por la liberación de vapor (Yuryev et al., 1995; Aarseth et al., 2006b). En la Tabla 4 se pueden observar valores de Da reportados en diferentes investigaciones.

Tabla 3: Aglutinantes usados en formulaciones para alimento extruidos, ventajas y desventajas de su uso

\begin{tabular}{|c|c|c|c|}
\hline Aglutinantes & $\begin{array}{c}\text { Contenido de ingrediente } \\
\text { en la formulación }\end{array}$ & Ventajas y desventajas & Referencia \\
\hline $\begin{array}{l}\text { Proteína soluble } \\
\text { en agua }\end{array}$ & $\begin{array}{l}97-412 \mathrm{~g} / \mathrm{kg} \\
\text { formulación (base seca) }\end{array}$ & $\begin{array}{l}\text {-Incrementa la viscoelasticidad del material } \\
\text { - Incrementa el contenido de nutrientes del producto final } \\
\text { - Resiste las condiciones de secado de los pellets } \\
\text { - Plastifica el producto }\end{array}$ & $\begin{array}{l}\text { Oterhals y } \\
\text { Samuelsen } \\
(2015)\end{array}$ \\
\hline Almidón & $100 \mathrm{~g} / \mathrm{Kg}$ formulación & $\begin{array}{l}\text { - Incrementa la expansión del pellet } \\
\text { - Incrementa la retención de agua } \\
\text { - Forma una estructura en forma de red } \\
\text { - Incrementa la elasticidad del material }\end{array}$ & $\begin{array}{l}\text { Sørensen et } \\
\text { al. (2010) }\end{array}$ \\
\hline $\begin{array}{l}\text { Melaza, } \\
\text { carbonato de } \\
\text { calcio }\end{array}$ & $\begin{array}{l}\text { Melaza: } \\
36 \mathrm{~g} / \mathrm{Kg} \text { formulación } \\
\text { Carbonato de calcio: } \\
10 \mathrm{~g} / \mathrm{Kg} \text { formulación }\end{array}$ & $\begin{array}{l}\text {-La melaza podría incrementar las interacciones } \\
\text { moleculares mediante la formación de puentes de } \\
\text { hidrogeno } \\
\text {-El carbonato de calcio podría neutralizar la acidez que } \\
\text { se genere por presencia de ácidos grasos libres y } \\
\text { contribuir al establecimiento de nuevas interacciones } \\
\text { moleculares mediante sus cargas eléctricas. }\end{array}$ & $\begin{array}{l}\text { Pantoja et al. } \\
\text { (2011) }\end{array}$ \\
\hline $\begin{array}{l}\text { Paredes } \\
\text { celulares de } \\
\text { levadura bajo } \\
\text { hidrólisis } \\
\text { enzimática }\end{array}$ & $\begin{array}{l}4.1-5.1 \mathrm{~g} / \mathrm{Kg} \\
\text { formulación (base seca) }\end{array}$ & $\begin{array}{l}\text { - Establece enlaces sólidos entre los componentes de la } \\
\text { formulación } \\
\text {-Incrementa la durabilidad del producto final } \\
\text { Incrementa la dureza del material }\end{array}$ & $\begin{array}{l}\text { Aarseth et al. } \\
(2006 b)\end{array}$ \\
\hline $\begin{array}{l}\text { Alginato y goma } \\
\text { guar }\end{array}$ & & $\begin{array}{l}\text {-Ambos disminuyen la digestibilidad aparente de las } \\
\text { proteínas y grasas } \\
\text {-Ambos reducen el consumo de alimento } \\
\text {-Ambos aumentan el contenido de agua de las heces } \\
\text {-Goma guar provocó retraso del alimento por el tracto } \\
\text { gastrointestinal } \\
\text {-Altos contenidos de goma guar reducen el crecimiento } \\
\text { y el contenido de materia seca y grasa de los peces }\end{array}$ & $\begin{array}{l}\text { Storebakken } \\
(1985)\end{array}$ \\
\hline Suero de leche & $52.6 \mathrm{~g} / \mathrm{Kg}$ base húmeda & $\begin{array}{l}\text {-Incrementó la durabilidad y la densidad de los } \\
\text { extruidos. }\end{array}$ & $\begin{array}{l}\text { Chevanan et } \\
\text { al. (2009) }\end{array}$ \\
\hline $\begin{array}{l}\text { Carboximetil } \\
\text { celulosa, } \\
\text { almidón de } \\
\text { maíz, goma } \\
\text { guar y gluten de } \\
\text { trigo }\end{array}$ & $30 \mathrm{~g} / \mathrm{Kg}$ & $\begin{array}{l}\text {-La digestibilidad aparente y los coeficientes de materia } \\
\text { seca, contenido de nitrógeno y lípidos fue más alto con } \\
\text { carboximetil celulosa, almidón de maíz y gluten de trigo. } \\
\text { Los valores de éstos parámetros fueron más bajos } \\
\text { cuando se usó goma guar. }\end{array}$ & $\begin{array}{l}\text { Fagbenro y } \\
\text { Jauncey } \\
(1995)\end{array}$ \\
\hline
\end{tabular}


Tabla 3 (continuación)

\begin{tabular}{|l|l|l|l|}
\hline $\begin{array}{l}\text { Proteína de } \\
\text { soja, girasol, } \\
\text { lupino, gluten } \\
\text { de maíz y colza }\end{array}$ & $250-326 \mathrm{~g} / \mathrm{kg}$ & $\begin{array}{l}\text {-Lupino dio la menor durabilidad al producto } \\
\text {-La proteína de girasol dio mayor dureza a los pellets } \\
\text {-Los pellets con mayor expansión fueron aquellos que } \\
\text { contenían lupino y colza } \\
\text {-El lupino presentó el menor grado de gelatinización y el } \\
\text { mayor índice de absorción de agua }\end{array}$ & $\begin{array}{l}\text { Kraugerud et } \\
\text { al. } 2011\end{array}$ \\
& & & \\
\hline
\end{tabular}

\section{Capacidad de absorción y pérdida de aceite}

La capacidad de absorción de aceite es la capacidad de los pellets de retener aceite en su estructura durante y después de la etapa de recubrimiento para lo cual se han desarrollado técnicas con sistemas al vacío (Sørensen et al., 2010). Este parámetro está relacionado con la capacidad de expansión, aunque es necesaria que la densidad aparente sea controlada para asegurar una velocidad de hundimiento adecuada. En este sentido, las condiciones de procesamiento mediante extrusión es determinante ya que dependiendo de las temperaturas programadas en cada sección del extrusor, la velocidad de tornillo y la velocidad de alimentación se podrá obtener pellets con mayor o menor expansión. Generalmente, altas temperaturas en el cabezal del extrusor conllevarán a incrementar el diferencial de presión, entre el cabezal y el medio ambiente, provocando la expansión de los materiales al salir del cabezal. Un pellet con mayor expansión tendrá mayor porosidad y por tanto mayor capacidad para absorber y retener aceite. La impregnación del aceite en los pellets puede realizarme mediante diversas técnicas como inmersión, pulverización e impregnación al vacío, entre otras.

Tabla 4: Valores de densidad aparente (Da) de alimentos extruidos para peces

\begin{tabular}{|c|c|c|c|c|}
\hline Dieta & Densidad aparente & Especie & Observaciones & Referencia \\
\hline $\begin{array}{l}\text { Dieta adicionada con } \\
\text { levadura roja }\end{array}$ & $636-649 \mathrm{~kg} / \mathrm{m}^{3}$ & Salmónidos & $\begin{array}{l}\text { A mayor temperatura de } \\
\text { extrusión menor } \mathrm{Da}\end{array}$ & $\begin{array}{l}\text { Aarseth et al. } \\
(2006 b)\end{array}$ \\
\hline $\begin{array}{l}\text { Pellets a base de harina } \\
\text { de maíz }\end{array}$ & $644 \mathrm{~kg} / \mathrm{m}^{3}$ & --- & $\begin{array}{l}\text { Los pellets con mayor } \mathrm{Da} \\
\text { presentan valores superiores } \\
\text { en la prueba de durabilidad } \\
\text { Holmen }\end{array}$ & $\begin{array}{l}\text { Mina-Boac, et } \\
\text { al. (1996) }\end{array}$ \\
\hline Dieta & $618-678 \mathrm{~kg} / \mathrm{m}^{3}$ & Salmo salar & $\begin{array}{l}\text { La prueba de durabilidad Doris } \\
\text { y la estabilidad en agua ( } 60 \\
\text { min) se correlaciona con } \mathrm{Da} \text {. } \\
\text { A menor contenido de } \\
\text { humedad de los pellets mayor } \\
\text { Da. }\end{array}$ & $\begin{array}{l}\text { Oehme et al. } \\
(2014)\end{array}$ \\
\hline $\begin{array}{l}\text { Harina de pescado } \\
\text { adicionada con proteína } \\
\text { bacteriana }\end{array}$ & $541-636 \mathrm{~kg} / \mathrm{m}^{3}$ & Salmónidos & $\begin{array}{l}\text { La expansión de los pellets se } \\
\text { correlacionó negativamente } \\
\text { con la Da. } \\
\text { La adición de proteína } \\
\text { bacteriana a la harina de } \\
\text { pescado reduce la } \mathrm{Da} \text {. }\end{array}$ & $\begin{array}{l}\text { Øverland et al. } \\
\text { (2007) }\end{array}$ \\
\hline Harina de pescado & $314-589 \mathrm{~kg} / \mathrm{m}^{3}$ & --- & $\begin{array}{l}\text { La dureza se correlacionó } \\
\text { positivamente con fracciones } \\
\text { de proteína soluble en agua, } \\
\text { grado de hidrólisis de proteína, } \\
\text { sal y Da }\end{array}$ & $\begin{array}{l}\text { Samuelsen et } \\
\text { al. (2013) }\end{array}$ \\
\hline $\begin{array}{l}\text { Harina de pescado } \\
\text { adicionadas con harina } \\
\text { de soja desengrasada } \\
\text { tostada y no tostada }\end{array}$ & $358-460 \mathrm{~kg} / \mathrm{m}^{3}$ & --- & $\begin{array}{l}\text { El diámetro y la expansión de } \\
\text { los pellets se correlacionó de } \\
\text { forma negativa con Da. } \\
\text { La dieta que contenía soya } \\
\text { desengrasada no tostada tuvo } \\
\text { la mayor Da. }\end{array}$ & $\begin{array}{l}\text { Sørensen et al. } \\
\text { (2009) }\end{array}$ \\
\hline $\begin{array}{l}\text { Combinación de harina } \\
\text { de pescado con proteína } \\
\text { de plantas }\end{array}$ & $\begin{array}{l}>520 \mathrm{~kg} / \mathrm{m}^{3} \text { antes } \\
\text { del secado }\end{array}$ & $\begin{array}{l}\text { Oncorhynchus } \\
\text { mykiss }\end{array}$ & $\begin{array}{l}\text { Estos valores de Da permiten } \\
\text { obtener velocidades de } \\
\text { hundimiento bajas después de } \\
\text { ser secados y recubiertos con } \\
\text { lípidos. }\end{array}$ & $\begin{array}{l}\text { Zhang et al. } \\
(2012 a)\end{array}$ \\
\hline
\end{tabular}


Los alimentos con alto contenido de energía se destinan a especies como el salmón (Hillestad y Johnsen, 1994). Algunos autores como Draganovic et al. (2011) que han trabajado con esta clase de dietas observaron que la capacidad de absorción de aceite se afectaba por la porosidad del producto, con un rango de absorción entre 27.9 y $63.3 \%$ teniendo una correlación positiva con la humedad en el pellet y el contenido de gluten de trigo. La expansión de los pellets tiene gran importancia en la capacidad de absorción de aceite, aunque debe tenerse en cuenta que una expansión demasiado alta podría generar pellets de baja durabilidad, por esta razón el radio de expansión debe ser optimizado (Yoshitomi, 2004; Sørensen et al., 2011).

Por otro lado, la pérdida de aceite de dietas de alto contenido energético es un problema porque el perfil nutricional del alimento se modifica. Además, si se forma una capa de aceite en la superficie del pellet puede producir aglomeración de pequeñas partículas. Algunos investigadores han estudiado las soluciones a esta problemática (Øverland et al., 2007; Sørensen et al., 2011), encontrando que esta se asocia más con la microestructura y la capacidad de expansión de los pellets (Sørensen et al., 2010). En este sentido, las condiciones de procesamiento y formulaciones son clave en el control de la pérdida de aceite (Sørensen et al., 2011). El aumento en la temperatura de acondicionamiento y del dado del extrusor promueve la expansión de la estructura y con ello se disminuye la pérdida de grasa en pellets (Øverland et al., 2007).

\section{Porosidad}

Las propiedades estructurales de los alimentos extruidos son importantes ya que determinan los parámetros de calidad física de los pellets además de su asimilación en el tracto digestivo. Una de las propiedades de mayor interés es la porosidad, ya que determina la capacidad de hundimiento y la habilidad de absorber aceite en su matriz en presencia de vacío (Øverland et al., 2007).

Existen diversos métodos para su determinación reportados en literatura. De acuerdo a la técnica experimental usada variará el rango de medida de la porosidad (Joardder et al., 2015). A modo de ejemplo se citan a continuación algunas de las técnicas usadas frecuentemente para medir la porosidad sobre diferentes tipos de materiales. Se puede usar Microscopía Electrónica de Barrido (SEM por sus siglas en inglés) y Microscopía Electrónica de Transmisión (TEM por sus siglas en inglés) para medir la geometría y la distribución de tamaño de poros entre $0.1 \mathrm{~nm}$ y $100 \mu \mathrm{m}$ (von Bradke et al., 2005 y Reese, 2006). Mediante la picnometría de gas se puede determinar la porosidad aparente, el volumen de poros para una distribución de tamaños de poro entre 0.2 y 80nm (Sereno et al., 2007). Con la intrusión de líquido (generalmente mercurio) se puede determinar la porosidad aparente, el diámetro y el tamaño de los poros, el rango de medida se comprende entre 10 y $10000 \mathrm{~nm}$ (Nagy y Vas, 2005). Por medio de difracción de rayos $X$ se puede determinar el área superficial y la distribución de tamaños de poro entre 5 y 20000nm (Wong, 1999). Otra técnica comúnmente usada es la porometría de flujo capilar, permite el diámetro, la superficie específica y la distribución de tamaños de poro entre $13 \mathrm{~nm}$ a $500 \mu \mathrm{m}$ (Jena y Gupta 2001).

En general, los alimentos para peces tienen altos contenidos de almidón y proteínas y durante el proceso de extrusión estas macromoléculas tienen comportamiento diferente. Por un lado, el almidón con el calor y humedad pierde su estructura cristalina gelatinizándose y adquiriendo propiedades elásticas, lo que da lugar a estructuras con mayor expansión (Lin et al., 2000; Acosta et al., 2006; Glencross et al., 2007; Chevanan et al., 2009). Por el otro lado, las proteínas con el calor y humedad se desnaturalizan e hidrolizan modificando su estructura primaría, secundaría, los enlaces peptídicos y las cadenas de aminoácidos. Cuando este material sale del dado del extrusor tiene un comportamiento plástico, resultando generalmente en productos con texturas fibrosas y porosas debido a la caída repentina de la presión (Prudêncio-Ferreira y Arêas, 1993; Chevanan et al., 2009). Otros factores como el contenido de humedad y el perfil de temperaturas usadas en el proceso de extrusión afectan la viscosidad del material fundido y las características del producto final (Chevanan et al., 2007, 2009). Draganovic et al. (2011) observaron que la adición de proteína vegetal (soya y trigo) a harina de pescado da por resultado extruidos con suficiente porosidad para conservar equilibrio entre la capacidad de absorción de aceite y la durabilidad adecuada que permita el almacenamiento, transporte y alimentación neumática del producto.

\section{CONCLUSIONES}

Las propiedades físicas en sus características y rangos, presentan relación directa con las condiciones de procesamiento de extrusión cocción y con la formulación de la dieta. Las variables de proceso como temperatura, humedad, velocidad de tornillo y tipo de materias primas utilizadas en la formulación, generan diversas respuestas dependiendo de su interacción, donde los parámetros físicos permiten tomar decisiones respecto a las condiciones óptimas operacionales, siendo una herramienta muy útil en la evaluación de materias primas no convencionales. Las diferencias en las propiedades físicas pueden relacionarse con la ingesta de alimento, el vaciado gástrico y palatabilidad, por tanto, el análisis de las propiedades físicas en procesos industriales debe llevarse de forma rutinaria, principalmente, cuando se incorporan nuevos ingredientes o si las condiciones de elaboración presentan cambios, siendo importante contar con métodos estandarizados para su evaluación. 


\section{AGRADECIMIENTOS}

Los autores agradecen a la Universidad del Cauca y al soporte económico del Sistema General de Regalías mediante el proyecto ID 3883.

\section{REFERENCIAS}

Aarseth, K.A., Attrition of Feed Pellets during Pneumatic Conveying: the Influence of Velocity and Bend Radius, Biosyst. Eng., 89(2), 197-213 (2004)

Aarseth, K.A., V. Perez y otros dos autores, Reliable pneumatic conveying of fish feed, Aquacult. Eng., 35, $14-25(2006 a)$

Aarseth, K.A., M. Sørensen y T. Storebakken, Effects of red yeast inclusions in diets for salmonids and extrusion temperature on pellet tensile strength: Weibull analysis, Anim. Feed Sci. Technol., 126, 75-91 (2006b)

Aas, T.S., B.F. Terjesen y otros nueve autores, Nutritional responses in rainbow trout (Oncorhynchus mykiss) fed diets with different physical qualities at stable or variable environmental conditions, Aquac. Nutr., $17,657-670$ (2011a)

Aas, T.S., M. Oehme y otros cuatro autores, Analysis of pellet degradation of extruded high-energy fish feeds with different physical quality in a pneumatic feeding system, Aquac. Eng., 44, 25-34 (2011b)

Acosta, B., I. Iglesias y otros tres autores, El ensayo de compresión diametral como alternativa a la caracterización mecánica de la cerámica de construcción, An. Mec. Fract., 22, 575-580 (2005)

Acosta, A.H., H.S. Villada y P.A. Prieto, Envejecimiento de almidones termoplásticos agrios de yuca y nativos de papa por microscopía de fuerza atómica, Información Tecnológica, 17, 71-78 (2006)

ASAE Standard S368.3, Compression test of food materials of convex shape, American Society of Agricultural Engineering, 1-14, St Joseph, MI, U.S.A. (1995)

ASAE Standard S269.4, Cubes, pellets, and crumbles: definitions and methods for determining density, durability, and moisture, American Society of Agricultural Engineering, 624-625, St Joseph, MI, U.S.A. (1997)

Baeverfjord, G., S. Refstie y otros dos autores, Low feed pellet water stability and fluctuating water salinity cause separation and accumulation of dietary oil in the stomach of rainbow trout (Oncorhynchus mykiss), Aquaculture, 261, 1335-1345 (2006)

Chen, F.L., Y.M. Wei y otros dos autores, System parameters and product properties response of soybean protein extruded at wide moisture range, J. Food Eng., 96, 208-213 (2010)

Chevanan, N., K. Muthukumarappan y otros dos autores, Effect of die dimensions on extrusion processing parameters and properties of DDGS-based aquaculture feeds, Cereal. Chem., 84, 389-398 (2007)

Chevanan, N., K. Muthukumarappan y K.A. Rosentrater, Extrusion studies of aquaculture feed using distillers dried grains with solubles and whey, Food Bioprocess Technol., 2, 177-185 (2009)

Chevanan, N., K. Muthukumarappan y otros dos autores, Effect of die dimensions on extrusion processing parameters and properties of DDGS-based aquaculture feed, Cereal. Chem., 84(4), 389-398 (2007)

Chinnaswamy, R., Basis of cereal starch expansion, Carbohydr. Polym., 21, 157-167 (1993)

Derby, C.D., F.H. Elsayed y otros cinco autores, Krill meal enhances performance of feed pellets through concentration-dependent prolongation of consumption by Pacific white shrimp, Litopenaeus vannamei, Aquaculture, 458, 13-20 (2016)

Draganovic, V., A.J. van der Goot y otros dos autores, Assessment of the effects of fish meal, wheat gluten, soy protein concentrate and feed moisture on extruder system parameters and the technical quality of fish feed, Anim. Feed Sci. Technol., 165, 238-250 (2011) 
Fagbenro, O. y K. Jauncey, Water stability, nutrient leaching and nutritional properties of moist fermented fish silage diets, Aquac. Eng., 14, 143-153 (1995)

FAO., Orientaciones técnicas para la pesca responsable. Desarrollo de la acuicultura. 6. Operaciones pesqueras, Uso de peces silvestres como alimento en acuicultura, Organización de las Naciones Unidas para la agricultura y la alimentación, 5(6), 1-92, (2013)

Glencross, B.D., M. Boot y G.L. Allan, A feed is only as good as its ingredients - a review of ingredient evaluation strategies for aquaculture feeds, Aquac. Nutr., 13, 17-34 (2007)

Glencross, B., N. Rutherford y W. Hawkins, A comparison of the growth performance of rainbow trout (Oncorhynchus mykiss) when fed soybean, narrow-leaf or yellow lupin meals in extruded diets, Aquac. Nutr., 17, 317-325 (2011)

Giraldo, G.I., C.D. Cruz y otros dos autores, Propiedades físicas del jugo de uchuva (physalis peruviana) clarificado en función de la concentración y la temperatura, Información Tecnológica, 28, 133-142 (2017)

Haubjerg, A., B. Simonsen y otros dos autores, Rheological properties as indicator for physicochemical processes affecting technical quality of extruded fish feed, AFSIA / EFCE WP Drying, 1-8 (2013)

Hillestad, M., y F. Johnsen, High-energy/low-protein diets for Atlantic salmon: effects on growth, nutrient retention and slaughter quality, Aquaculture, 124, 109-116 (1994)

Hilton, J.W., C.Y. Cho y S.J. Slinger, Effect of extrusion processing and steam pelleting diets on pellet durability, pellet water absorption and the physiological response of rainbow trout (Salmo Gairdneri), Aquaculture, 25, 185-194 (1981)

ISO 5311. Fertilizers-Determination of Bulk Density (tapped). International Organization for Standardization, Geneva, Switzerland (1992)

Jena, A. y K. Gupta, An innovative technique for pore structure analysis of fuel cell and battery components using flow porometry, J. Powder Sources, 96, 214-219 (2001)

Joardder, M.U.H., C. Kumar y otros dos autores, A micro-level investigation of the solid displacement method for porosity determination of dried food, J. Food Eng., 166, 156-164 (2015)

Kaliyan, N. y R.V. Morey, Factors affecting strength and durability of densified products, Biomass Bioenerg., 33, 337-359 (2009)

Kraugerud, O.F., H.Y Jørgensen, y B. Svihus, Physical properties of extruded fish feed with inclusion of different plant (legumes, oilseeds, or cereals) meals, Anim. Feed Sci. Technol., 163, 244-254 (2011)

Lekang, O.I., J. Andersen y otros dos autores, Devices and methods for measuring physical properties of particulate material (Utstyr og metoder for maling av fysiske egenskaper ved partikkelmateriale), Technical note 106/91. In Norwegian. Department of Mathematical Sciences and Technology, The Norwegian University of Life Sciences, Ås, Norway (1991)

$\mathrm{Li}, \mathrm{M}$, y T.C. Lee, Effect of cysteine on the functional properties and microstructures of wheat flour extrudates, J. Agric. Food Chem., 44, 1871-1880 (1996)

Lin, S., H.E. Huff y F. Hsieh, Texture and chemical characteristics of soy protein meat analog extruded at high moisture, J. Food Sci., 65, 264-269 (2000)

Mina-Boac, J., R.G. Maghirang y M.E. Casada, Durability and breakage of feed pellets during repeated elevator handling, A.S.A.B.E., Paper number 066044, (2006)

Morken, T., O.F. Kraugerud y otros cuatro autores, Sodium diformate and extrusion temperature affect nutrient digestibility and physical quality of diets with fish meal and barley protein concentrate for rainbow trout (Oncorhynchus mykiss), Aquaculture, 317, 138-145 (2011) 
Morken, T., O.F. Kraugerud y otros cinco autores, Effects of feed processing conditions and acid salts on nutrient digestibility and physical quality of soy-based diets for Atlantic salmon (Salmo salar), Aquac. Nutr., 18, 21-34 (2012)

Nagy, V. y L.M. Vas, Pore characteristic determination with mercury porosimetry in polyester staple yarns, Fibres Text. East. Eur., 13(3), 21-26 (2005)

Oehme, M., T.S. Ass y otros cinco autores, Effect of dietary moisture content of extruded diets on physical feed quality and nutritional response in Atlantic salmon (Salmo salar), Aquac. Nutr., 20, 451-465 (2014)

Osorio, A.M, J.M Marín y G. Restrepo, Comportamiento reológico de pulpas de cuarzo a diferentes concentraciones del sólido, Información Tecnológica, 26, 135-142 (2015)

Oterhals, A. y T.A. Samuelsen, Plasticization effect of solubles in fishmeal, Food Res. Int., 69, 313-321 (2015)

Øverland, M., O.H. Romarheim y otros tres autores, Technical quality of dog food and salmon feed containing different bacterial protein sources and processed by different extrusion conditions, Anim. Feed Sci. Technol., 134, 124-139 (2007)

Øverland, M. y M. Sørensen y otros cuatro autores, Pea protein concentrate substituting fish meal or soybean meal in diets for Atlantic salmon (Salmo salar). Effect on growth performance, nutrient digestibility, carcass composition, gut health, and physical feed quality, Aquaculture, 288, 305-311 (2009)

Øvrum Hansen, J. y T. Storebakken, Effects of cellulose inclusions on pellet quality and digestibility of main nutrients and minerals in rainbow trout (Oncorhynchus mykiss), Aquaculture, 272, 458-465 (2007)

Pantoja, O., S.M. Sánchez y J.L. Hoyos, Obtención de un alimento extruido para tilapia roja (Oreochromis spp) utilizando ensilaje biológico de pescado, Biotecnología en el sector agropecuario y agroindustrial, 9(2), 178-187 (2011)

Prudêncio-Ferreira, S.H. y J.G. Arêas, Effect of phospholipid on protein structure and solubility in the extrusion of lung proteins, Food Chem., 47, 111-119 (1993)

Reese, J.P., New Nanotechnology Research, 1ª Ed., 69-93. Nova Science Publishers, Inc, New York, U.S.A. (2006)

Samuelsen, T.A., S.A. Mjøs y Å. Oterhals, Impact of variability in fishmeal physicochemical properties on the extrusion process, starch gelatinization and pellet durability and hardness, Anim. Feed Sci. Technol., 179, 77-84 (2013)

Samuelsen, T.A. y Å. Oterhals, A powdered protein composition having binding properties adapted for use as protein source and binder in a formulated feed. WO 2000035299 A1, 22 de junio (2000)

Sereno, A.M., M.A. Silva y L. Mayor, Determination of particle density and porosity in foods and porous materials with high moisture content, Int. J. Food Prop., 10(3), 455-469 (2007)

Serna-Cock, L., M. Velásquez y A.A. Ayala, Efecto de la ultrafiltración sobre las propiedades reológicas de gelatina comestible de origen bovino, Información Tecnológica, 21, 91-102 (2010)

Sørensen, M., A review of the effects of ingredient composition and processing conditions on the physical qualities of extruded high-energy fish feed as measured by prevailing methods, Aquac. Nutr., 18, 233-248 (2012)

Sørensen, M., T. Morken y otros dos autores, Pea and wheat starch possess different processing characteristics and affect physical quality and viscosity of extruded feed for Atlantic salmon, Aquac. Nutr., 17, 326-336 (2011)

Sørensen, M., G. Nguyen y otros dos autores, Starch source, screw configuration and injection of steam into the barrel affect the physical quality of extruded fish feed, Aquac. Res., 41, 419-432 (2010)

Sørensen, M., N. Stjepanovic y otros tres autores, Soybean meal improves the physical quality of extruded fish feed, Anim. Feed Sci. Technol., 149, 149-161 (2009) 
Storebakken, T., Binders in fish feeds I. Effects of alginate and guar gum on growth, digestibility, feed intake and passage through the gastrointestinal tract of rainbow trout, Aquaculture, 47, 11-26 (1985)

Thomas, M. y A.F.B. van der Poel, Physical quality of pelleted animal feed 1. Criteria for pellet quality, Anim. Feed Sci. Technol., 61, 89-112 (1996)

Tyapkova, O., R. Osen y otros cuatro autores, Replacing fishmeal with oilseed cakes in fish feed e A study on the influence of processing parameters on the extrusion behavior and quality properties of the feed pellets, Int. J. Food Eng., 191, 28-36 (2016)

Vanegas, D.M. y M.E. Ramírez, Correlación del Crecimiento de Pseudomonas fluorescens en la Producción de Polihidroxialcanoatos de Cadena Media (PHA $A_{M C L}$ ) mediante Modelos Primarios de Gompertz, Logístico y Baranyi, Información Tecnológica, 27, 87-96 (2016)

Von Bradke, M., F. Gitzhofer y R. Henne, Porosity determination of ceramic materials by digital image analysis-a critical evaluation, Scanning, 27(3), 132-135 (2005)

Weibull, W., A statistical theory of the strength of materials, Royal Swedish Institute Engineering Research, 151, 1-45 (1939)

Winowiski, T.S., Pellet quality in animal feeds: Technical Bulletin, A.S.A., FT21 (1995)

Wong, P.Z., Methods in the Physics of Porous Media. Academic Press, San Diego, U.S.A. (1999)

Wood, J.F., The functional properties of feed raw materials and their effect on the production and quality of feed pellets, Anim. Feed Sci. Technol., 18, 1-17 (1987)

Yoshitomi, B., Effect of extrusion cooking temperature on the microstructure of extruded pellets, Fish. Sci., 70, 1157-1163 (2004)

Yuryev, V.P., D.V. Zasypkin y otros dos autores, Expansion ratio of extrudates prepared from potato starchsoybean protein mixtures, Carbohydr. Polym., 26, 215-218 (1995)

Zhang, Y., M. Øverland y otros cuatro autores, Optimizing plant protein combinations in fish meal-free diets for rainbow trout (Oncorhynchus mykiss) by a mixture model, Aquaculture, 360-361, 25-36 (2012a)

Zhang, Y., M. Øverland y otros cinco autores, Optimal inclusion of lupin and pea protein concentrates in extruded diets for rainbow trout (Oncorhynchus mykiss), Aquaculture, 344-349, 100-113 (2012b) 